\title{
O estudo da produção documental e a memória organizacional em ambientes empresariais
}

\author{
Natália Marinho do Nascimento \\ Doutoranda; Universidade Estadual Paulista "Júlio de Mesquita Filho", Marília, SP, Brasil; \\ natalianascimento_@hotmail.com \\ Marcia Cristina de Carvalho Pazin Vitoriano \\ Doutora; Universidade Estadual Paulista "Júlio de Mesquita Filho", Marília, SP, Brasil; \\ marciapazin@marilia.unesp.br
}

\begin{abstract}
Resumo: O estudo da produção documental permite que o arquivista compreenda quais são as funções e atividades que estão materializados em documentos. É por meio desse estudo que a gestão documental se inicia, possibilitando também a implantação da gestão da informação, da gestão do conhecimento e da memória organizacional. O objetivo deste trabalho é identificar como a memória organizacional contribui para as empresas e como a produção documental contribui para a preservação da memória organizacional. O presente trabalho constitui-se em pesquisa qualitativa, de caráter exploratório, utilizando-se como procedimento metodológico a pesquisa bibliográfica. Evidencia-se que a memória organizacional está estritamente ligada à gestão da informação e do conhecimento e que é a partir desta memória que os repositórios são transformados em repertórios de conhecimento, que subsidiam o processo decisório, garantindo que as organizações obtenham vantagem competitiva. Como resultado, entende-se que o estudo da produção documental e de seu contexto é o que vai dar suporte para os profissionais desenvolverem a memória organizacional nos ambientes empresariais.
\end{abstract}

Palavras-chave: Memória Organizacional. Produção Documental. Ambientes Empresariais. Gestão da Informação. Gestão do Conhecimento.

\section{Introdução}

As organizações são imprescindíveis para a sociedade e inerentes de complexidade. Trabalhar a informação em ambientes empresariais, perceber todos os elementos que as compõem (tanto as empresas quanto suas informações) e, mais do que isso, estabelecer as relações possíveis entre estes elementos, não é uma tarefa nada fácil. 
Organizações são unidades sociais, intencionalmente construídas e reconstruídas a fim de atingir objetivos específicos. Trata-se de conceito amplo, que envolve uma série de entidades organizadas hierarquicamente, com base num planejamento intencional, visando à concretização de seus objetivos. Por isso, as organizações pressupõem a especialização do trabalho, a partir de uma estrutura administrativa e de direção (ETZIONI, 1976).

Para efeito da discussão a que se propõe este trabalho, trataremos especificamente das organizações de natureza empresarial, aquelas constituídas com finalidade econômica, que visam explorar determinado ramo de negócio e oferecer ao mercado bens e serviços.

No contexto da competitividade econômica, cada empresa constrói, ao longo de sua existência, estratégias para consecução de seus objetivos. Com isso, forma-se um repertório de conteúdos representativos de suas atividades, processos e de sua cultura organizacional. Esse repertório constituirá o que poderíamos denominar como a memória daquela unidade social.

É da natureza das organizações que parte de suas vivências se constituam como memória. Alguns elementos são muito discutidos nos ambientes empresariais e se constituem como uma das bases dessa memória das organizações. Estes elementos são os dados, a informação e o conhecimento. Se estes elementos não forem trabalhados, interpretados e utilizados, não farão diferença para a gestão empresarial. Atribuir o devido valor estratégico ao conteúdo informacional, como no caso do conhecimento organizacional, estreitamente relacionado com a memória, resultará em benefícios para as empresas de diversas maneiras.

A partir da existência de programas de gestão documental, de gestão da informação e de gestão do conhecimento, as empresas permitem que estes elementos sejam tratados, organizados e armazenados em ambientes controlados, de modo a possibilitar a construção de um arcabouço de memória que possa ser utilizado no futuro. Diante disso, é importante para a preservação da memória de cada empresa, refletir sobre as condições de tratamento do acervo documental, tanto do ponto de vista da conservação física dos documentos, como também pensar no tratamento da informação orgânica 
representada por eles, além da seguridade dos recursos tecnológicos e suas possíveis vulnerabilidades, ou seja, no risco de perda dos dados, informações e conhecimentos devido à rápida obsolescência dos suportes ou pelo mau gerenciamento dos sistemas e processos.

Nessa perspectiva, pretende-se evidenciar como a produção de dados e informações (que surgem para o cumprimento de atividades/tarefas pelos sujeitos organizacionais e são armazenados em repositórios físicos ou digitais) pode produzir sentido e contribuir de maneira efetiva para que as empresas estabeleçam diferenciais competitivos em relação àquelas que não valorizam a memória organizacional como elemento estratégico.

Salienta-se a importância do trabalho do profissional da informação, especificamente o arquivista para essa atividade, pois são estes profissionais que irão lidar com os documentos desde a sua produção até a sua guarda permanente ou eliminação, ou seja, existe um papel crucial para o arquivista na gestão documental, bem como com a informação e o conhecimento pensando nas questões estratégicas, de memória e história.

Diante disso, este trabalho apresenta as seguintes questões-problema: $\mathrm{O}$ que a memória organizacional representa para os ambientes empresariais? Qual a importância do estudo da produção documental para a preservação da memória organizacional?

O objetivo configura-se em identificar como a memória organizacional contribui para as empresas e como o estudo da produção documental contribui para a preservação da memória organizacional.

Neste contexto, é importante identificar a existência de dois conceitos relacionados ao uso da memória nas empresas: a memória organizacional e a memória institucional. A memória organizacional está ligada totalmente ao processo decisório, em como os gestores utilizam a informação retrospectiva para subsidiar decisões e garantir vantagens sobre a concorrência, enquanto a memória institucional está voltada aos aspectos da história da empresa e às questões de preservação de seu patrimônio cultural. Como delimitação do tema a ser desenvolvido neste artigo, utiliza-se o conceito de memória organizacional. 
Este artigo configura-se em uma pesquisa qualitativa, de caráter exploratório, cujo procedimento utilizado é a pesquisa bibliográfica. Também é resultado das discussões realizadas durante a disciplina "Políticas de preservação da memória e conhecimento organizacional: interfaces com a gestão do conhecimento", da linha de pesquisa Gestão, Mediação e Uso da Informação do Programa de Pós-Graduação em Ciência da Informação da Faculdade de Filosofia e Ciências - UNESP, campus Marília. O trabalho encontra-se dividido em três partes. Primeiramente, apresenta-se uma abordagem sobre a memória organizacional em ambientes empresariais, a seguir aspectos do estudo da produção documental e, para finalizar, uma análise sobre como a produção documental pode contribuir para a constituição da memória organizacional.

\section{Memória organizacional em ambientes empresariais}

Entende-se que a memória se constitui em um fenômeno importante para a sociedade, tendo em vista que os indivíduos possuem a necessidade de fazer referência ao passado. A memória permite que acontecimentos, experiências, manifestações culturais e costumes sejam preservados ao longo do tempo.

Pensando no âmbito das empresas, acredita-se que a memória pode trazer diferenciais consideráveis para o processo administrativo, dentre estes: a redução do retrabalho e a reutilização de informações e conhecimento previamente adquiridos. Esta reutilização se dá com a possibilidade de reelaborar dados existentes nos repositórios informacionais, sejam eles sistemas ou arquivos, atribuindo novo sentido aos registros armazenados que, até então, não tenham sido utilizados em toda sua potencialidade.

Buscando esclarecer o fenômeno e pensá-lo nos ambientes empresariais, é importante estabelecer um referencial sobre o uso da memória em seus múltiplos aspectos.

Os autores que pesquisam a memória como fenômeno social sempre destacam alguns elementos em suas reflexões, um deles é o esquecimento: toda memória está atrelada ao esquecimento. A memória de um fato ou uma ação 
pressupõe a seleção de um conjunto de informações e representações significativas para uma pessoa ou grupo.

Ao mesmo tempo, considerando-se a prevalência do registro documental na civilização moderna, evidencia-se a existência, em certa medida, no contexto empresarial, de uma dependência da memória em relação à existência de registro sobre fatos e ações. Assim, a ausência de registro colabora para o esquecimento.

Além disso, a memória não é um processo linear. Assim como ocorre com os indivíduos, grupos sociais produzem memórias alternadas, onde o que se lembra e o que se esquece são componentes de um mesmo conjunto de variáveis, que dependem de questões psicológicas relacionadas ao desenvolvimento pessoal ou da vida em grupo. Ela também envolve lembranças selecionadas: o que se lembra e o que se esquece são componentes, em cada pessoa, de um mesmo conjunto de variáveis.

Pierre Nora (1993) apresenta algumas considerações sobre o tema:

A memória é a vida sempre carregada por grupos vivos e, nesse sentido, ela está em permanente evolução, aberta a dialética de lembrança e do esquecimento, inconsciente de suas deformações sucessivas, vulnerável a todos os usos e manipulações, susceptível de longas latências e de repentinas revitalizações [...] a memória é um fenômeno sempre atual, um elo vivido no eterno presente [...] a memória não se acomoda a detalhes que a confortam; ela se alimenta de lembranças vagas, telescópicas, globais ou flutuantes, particulares ou simbólicas, sensível a todas as transferências, cenas, censura ou projeções [...] a memória instala a lembrança no sagrado [...] a memória emerge de um grupo que ela une o que quer dizer, como Halbwachs o fez, que há tantas memórias quantos grupos existem; que ela é, por natureza, múltipla e desacelerada, coletiva, plural e individualizada [...] a memória se enraíza no concreto, no espaço, no gesto, na imagem, no objeto (NORA, 1993, p. 9).

Quando o autor apresenta a memória como "um elo vivido no eterno presente", observa-se que o passado é a característica principal da memória, mas no que tange à sua construção, ela ocorrerá pelas demandas que o presente faz. É no presente que a memória fará diferença sobre a sociedade e garantirá também sua identidade, pois como afirma Izquierdo, “[...] o acervo de nossas 
memórias faz com que cada um de nós seja o que é, com que sejamos, cada um, um indivíduo, um ser para o qual não existe outro idêntico.” (IZQUIERDO, 2002, p. 5). Apesar de voltada aos indivíduos, a colocação do autor pode ser aplicada aos grupos sociais. Cada grupo, organização, empresa, cria uma identidade própria a partir da construção de uma cultura que tem na memória coletiva um de seus elementos.

Segundo Delmas, “[...] lembrar é uma necessidade prática da vida cotidiana de qualquer pessoa ou instituição, é o resultado da necessária continuidade da vida dos indivíduos como organismos, isto é, a continuidade de cada uma de suas ações.” (DELMAS, 2010, p. 26-27). Pazin-Vitoriano aplica o conceito de memória para a administração, afirmando que a memória de uma empresa se constitui na “[...] representação, ou o conjunto de representações, que o grupo faz do passado dessa organização, a partir dos elementos disponíveis para isso.” (PAZIN-VITORIANO, 2013, p. 922).

No ambiente empresarial, a memória se constitui no resultado da interação do grupo. Sua construção é marcada pela intencionalidade, pois os indivíduos decidem o que é relevante ou não para ser lembrado ou esquecido e isso é o que resultará em sua própria identidade. Neste sentido, o conceito de memória está estritamente relacionado à cultura organizacional (por se tratar de vários indivíduos cada um com seus valores, crenças, costumes, modo de pensar que juntos formam a cultura organizacional) e às questões de identidade de uma empresa.

Embora alguns autores trabalhem vários destes elementos como se fossem similares, há uma diferença marcante entre os dois usos da memória utilizados no ambiente empresarial, que se configuram em diferentes conceitos: a memória institucional (MI) e a memória organizacional (MO). Oliveira (2014) organizou em quadro um panorama dos conceitos de memória que diversos autores utilizaram no decorrer dos anos. Neste quadro, em alguns momentos, a definição de uma se confunde com a de outra. Para a finalidade deste artigo, utiliza-se um recorte de duas definições que apresentam de forma evidente as diferenças entre os dois conceitos e sua complementaridade. 
Quadro 1 - Panorama dos conceitos de Memória Institucional e Memória Organizacional.

\begin{tabular}{|c|c|}
\hline $\begin{array}{c}\text { CONCEITUANDO MEMÓRIA INSTITUCIONAL (MI) E } \\
\text { MEMÓRIA ORGANIZACIONAL (MO) }\end{array}$ & AUTORES \\
\hline $\begin{array}{l}\text { (MI) - Na perspectiva do tempo, seria o retorno elaborado de tudo aquilo } \\
\text { que contabilizamos na história como conquistas, legados, acontecimentos, } \\
\text { mas também vicissitudes, servidões, escuridão. }\end{array}$ & $\begin{array}{c}\text { COSTA } \\
\text { (1997, p. 47) }\end{array}$ \\
\hline $\begin{array}{l}\text { (MO) - Acervo de informação, conhecimentos e práticas, agregados e } \\
\text { retidos pela organização ao longo de sua existência, utilizados para o } \\
\text { suporte às suas atividades, seus processos decisórios e para a preservação } \\
\text { do seu capital intelectual, potencializando a gestão do conhecimento. }\end{array}$ & MENEZES \\
(2006, p. 31)
\end{tabular}

Fonte: Seleção a partir de Oliveira (2014, p. 257-258).

Observa-se que enquanto a MI está voltada para as questões culturais e históricas da empresa sendo, portanto, mais abrangente, a MO está voltada para o aspecto gerencial, ou seja, para a utilização técnica e administrativa das informações que foram produzidas ou recebidas no cumprimento de uma função/atividade, que no que diz respeito, são resultantes das relações ocorridas nesse ambiente e que se configuram no que se entende por informações orgânicas.

As informações orgânicas podem ser definidas como "[...] um conjunto de informações sobre um determinado assunto, materializada em documentos arquivísticos que, por sua vez, mantêm relações orgânicas entre si e foram produzidos no cumprimento das atividades e funções da organização" (CARVALHO; LONGO, 2002, p. 115). Destaca-se que nessa definição estão contempladas as informações produzidas no interior da organização e também aquelas recebidas que possuam relação direta com o cumprimento de funções/atividades da organização.

No levantamento sobre o tema, realizado por Melgar-Sasieta, Beppler e Pacheco (2011), os autores fazem uma compilação de abordagens de diversos autores e concluem que:

A memória organizacional (MO) pode ser definida como um sistema capaz de armazenar as coisas percebidas, experimentadas ou vividas para além da duração da ocorrência atual, e permitir recuperá-las posteriormente (Lehner e Maier, $2000^{1}$ ). É o conhecimento de como fazer as coisas, a forma de abordar os problemas e questões, como 
tratamos uns aos outros (Jackson, 2007²). A memória organizacional se preocupa com a reutilização e compartilhamento deste tipo de conhecimento (Ackerman e Hadverson, 2000 ${ }^{3}$ ) para usá-lo nas atividades atuais, melhorando assim a eficácia organizacional (Stein, 19954) (MELGAR-SASIETA; BEPPLER; PACHECO, 2011, p. 2).

Diante disso, podemos dizer que a memória organizacional consiste no valor que os indivíduos atribuem aos dados, informação e conhecimento, do ponto de vista do uso desses conteúdos para a gestão, auxiliando no processo decisório, já que estes possibilitam o embasamento de ações tomadas no presente, a partir da utilização das informações retrospectivas.

Dados podem ser considerados como o elemento inicial de qualquer ato de conhecimento: uma impressão, uma premissa, um princípio, apresentado de forma direta e imediata à consciência, que servirá de base ou pressuposto no processo cognitivo (HOUAISS, 2010). Miranda (1999, p. 286) afirma que os dados são considerados um “[...] conjunto de registros qualitativos ou quantitativos conhecidos que organizado, agrupado, categorizado e padronizado adequadamente transforma-se em informação".

Já a informação, é entendida como o "[...] subconjunto de dados que adquirem significado para o receptor dos mesmos [...] um dado passa a ser informação quando adquire significação para seu receptor, um dado é ou não informação dependendo de seu significado para esse receptor." (PÉREZMONTORO GUTIERRÉZ, 2004, p. 9, tradução nossa). Informações são constituídas por "[...] dados dotados de relevância e propósito." (DRUCKER, apud DAVENPORT; PRUSAK, 2003, p.4). É a resposta a um questionamento o que produz a informação.

No caso do conhecimento, considera-se a informação compreendida e apropriada pelo sujeito de acordo com suas próprias condições cognitivas. Como afirmam Davenport e Prusak (2003),

O conhecimento é uma mistura fluida de experiência condensada, valores, informação contextual e insight experimentado, a qual proporciona uma estrutura para a avaliação e incorporação de novas experiências e informações. Ele tem origem e é aplicado na mente dos conhecedores. Nas organizações, ele costuma estar embutido não só em documentos ou repositórios, mas também em 
rotinas, processos, práticas e normas organizacionais (DAVENPORT; PRUSAK, 2003, p. 6).

Porém, é importante perceber que, quando em um arquivo ou repositório, informação e conhecimento estão apenas armazenados e não são utilizados, eles retornam à condição de dados. Por isso, é evidente a necessidade do arquivista trabalhar com dados, informações e conhecimentos, num processo constante de realimentação.

Infere-se ainda que os elementos dados, informação e conhecimento, são elementos complexos que sofrem a influência de muitos fatores para a aproximação de uma significação.

Simião (c2009) aborda a questão quando diz que:

A Memória Organizacional deve permitir responder às principais questões que se faça sobre a organização, seu ambiente, seus processos e produtos. Deve ainda funcionar como um serviço inteligente e ativo, capaz de colocar à disposição de quem tenha que executar determinada tarefa, no tempo certo, as informações necessárias para o trabalho (SIMIÃO, c2009).

Para Bellotto, a memória é "[...] referenciadora, e não recolhedora ou armazenadora. Os documentos existem nos seus lugares, sem que se tente reunilos materialmente. Basta que a informação esteja captada, o objeto identificado, localizado e disponível para o pesquisador" (BELLOTTO, 2004, p. 274). Isso significa que os profissionais que trabalham com a memória organizacional devem possuir competências informacionais ${ }^{5}$ adequadas para dar um sentido ao que já está organizado e armazenado, ou seja, para a construção de conteúdos representativos, bem como perceber quais são as necessidades dos usuários.

Pode-se dizer, então, que a construção de um modelo de memória organizacional teria como objetivos registrar, organizar e disseminar o conhecimento produzido por uma empresa, de modo a cumprir uma série de metas, conforme proposto por Freire et al (2012):

Pode-se dizer que o conhecimento é inerente às pessoas que formam a organização e que um modelo de memória organizacional deve ter como metas: evitar a perda do conhecimento intelectual quando um especialista deixa a 
empresa; explorar e reutilizar a experiência adquirida nos projetos passados para evitar a repetição de erros; melhorar a circulação e comunicação da informação na organização; integrar o saber fazer de diferentes setores da empresa e melhorar o processo de aprendizagem individual e coletiva de toda a organização (FREIRE et al., 2012, p. 44).

Percebe-se que a memória organizacional vai além da guarda de acervos documentais, como aqueles existentes nos arquivos. A existência desses repositórios é essencial, claro, uma vez que é a partir do registro que é possível obter o conteúdo necessário à produção de conhecimento. Nesse sentido, a memória organizacional pode ser considerada como o processo pelo qual se dá a reutilização e ressignificação do documento e de seu conteúdo, fazendo aflorar o valor secundário do acervo. Como salienta Freire (2012), a memória:

[...] se configura numa estrutura de rede, tanto de pessoas, quanto de artefatos, experiências e processos interligados, de modo a configurar uma estrutura de conteúdos e conhecimentos preservados ao longo do tempo e que se articulam de acordo com as necessidades organizacionais em diferentes situações (FREIRE et al, 2012, p. 44).

Por sua característica processual, a memória organizacional necessita de um sistema de gestão da informação que articule repositórios e usuários, além de garantir a correta gestão documental dos documentos produzidos.

Ao mesmo tempo, ela colabora para que seja implantado um sistema de gestão do conhecimento que articule produtores de documentos e informações, de modo a garantir o registro e a disseminação do conhecimento tácito que circula na empresa. A existência desses sistemas, e sua integração, será a raiz do que denominamos como memória organizacional.

Cabe destacar, porém, que esse não é um processo simples.

Embora seja conhecida e aceita a importância de saber como manter, gerenciar e compartilhar o conhecimento, poucas organizações contam com um adequado sistema de gestão do conhecimento estratégico, o qual inclua um instrumento que faça a função de memória organizacional, pois os sistemas existentes são, na maioria dos casos, aplicações de suporte aos processos de negócio ou aos seus processos de apoio. (MACEDO, 2003, p. 20). 
Considera-se um dos maiores problemas decorrentes do que Macedo (2003) apresenta, o fato de que no Brasil não existe legislação que proponha políticas de preservação para a memória organizacional no ambiente privado, tanto de entidades quanto de empresas. Na Lei 8.159 de 1991 (BRASIL, 1991), que estabelece a política nacional para arquivos públicos e privados, não há possibilidade de imposição de preservação de arquivos privados, o que, de certa forma, contribui para a redução de seu interesse em desenvolver a memória. Quando as empresas ainda não possuem conhecimento sobre como utilizar a memória como ferramenta para a estratégia competitiva, cabe aos arquivistas trabalhar para a construção da memória organizacional.

Como já dito anteriormente, trata-se de um elemento de grande complexidade, já que durante o processo devem ser identificadas as informações e conhecimentos realmente relevantes para a organização, as necessidades dos usuários e evidenciar claramente para os gestores que a memória organizacional resulta em subsídio para o processo decisório, agregando, consequentemente, vantagem competitiva ${ }^{6}$ para a empresa.

\section{Reflexões sobre o estudo da produção documental em ambientes empresariais}

Segundo a Lei Federal 8.159, de 8 de janeiro de 1991, gestão de documentos é:

[...] o conjunto de procedimentos e operações técnicas referentes à sua produção, tramitação, uso, avaliação e arquivamento em fases corrente e intermediária, visando a sua eliminação ou recolhimento para a guarda permanente (BRASIL, 1991, doc. não paginado).

Observa-se desde a legislação que a produção de documentos é a primeira etapa que constitui a gestão documental que, por sua vez, garante às organizações um controle efetivo das informações produzidas e recebidas no cumprimento de sua função. A gestão documental, exercida desde a produção, proporciona a redução da massa documental e a otimização dos espaços destinados ao armazenamento de documentos. Alguns autores podem conceituar 
de maneira distinta a gestão documental, podem incluir mais ou menos etapas, porém todos eles apresentam a produção documental como etapa inicial do processo.

Em alguns momentos percebe-se certa confusão no que tange aos termos gestão documental (GD) e gestão da informação (GI), observa-se isso no momento da verificação in loco, onde muitas empresas dizem que realizam GI e na verdade realizam apenas a GD, que não é a mesma coisa. Para Ponjuán Dante (2004), a gestão documental,

[...] é um processo administrativo que permite analisar e controlar sistematicamente ao longo do seu ciclo de vida, a informação registrada que é criada, recebida, mantida e utilizada na organização, relacionadas à missão, objetivos e operações. Também é considerado um processo para manter as informações em um formato que permite o acesso em tempo útil, por isso são necessárias tarefas e procedimentos para cada fase e uso desta informação registrada que é evidência das atividades e operações das organizações e permitir-lhes maior eficiência (PONJUÁN DANTE, 2004, p. 129 , tradução nossa).

A GI, por outro lado, pode ser definida como:

A aplicação dos princípios de administração na aquisição, organização, controle, disseminação e uso de informação relevante que sustente a operação efetiva de organizações de diferentes tipos. Por 'informação' se entende todos os tipos de recursos informativos com valor agregado, que tenham origem no interior da organização ou fora dela. Inclui dados, registros e arquivos relacionados às funções da organização, tais como recursos humanos, marketing e de inteligência competitiva (provindos de distintas fontes). O gerenciamento da informação engloba conceitos como qualidade, valor, posse, uso e segurança de informação no contexto de desempenho da organização (WILSON, 2003, p. 263, tradução nossa).

Assim, do ponto de vista da informação orgânica, é preciso que haja um programa de gestão documental funcionando com sucesso para que a empresa consiga implantar também a GI, e isso não significa que seja uma relação de subordinação. Neste caso, a gestão documental é um componente da gestão da informação. Assim a GI se nutre da GD e esta utiliza grande parte da plataforma da GI para que seus processos sejam mais eficientes (PONJUÁN DANTE, 2004, 
p.139, tradução nossa). Por isso, a análise e o controle da produção documental se configuram em elementos essenciais para os ambientes empresariais.

Entende-se que é por meio da produção documental que o arquivista estuda o contexto de produção dos documentos, adquirindo assim um conhecimento rico e detalhado da empresa que proporcionará a ele condições para aplicar as técnicas arquivísticas, bem como para trabalhar com os dados, a informação e o conhecimento como elementos estratégicos da empresa, resultando em tratamento, organização, armazenamento e uso de qualidade, de modo que de fato as informações orgânicas sejam utilizadas como subsídio para o processo decisório. Como afirma Pazin (2005), todas essas etapas estão interligadas,

O processo de organização do arquivo de qualquer instituição implica a realização de diversas etapas que possibilitem a compreensão e codificação dos documentos em diversos níveis, desde seu reconhecimento (Diagnóstico da Produção Documental), passando pela inclusão de cada tipo documental numa lógica de organização (Classificação), até o estabelecimento de critérios de valoração, visando determinar a preservação ou eliminação dos documentos (Avaliação) (PAZIN, 2005, p. 5).

Para Bernardes e Delatorre, a produção de documentos é “[...] a elaboração padronizada de tipos/séries documentais, implantação de sistemas de organização da informação e aplicação de novas tecnologias aos procedimentos administrativos" (BERNARDES; DELATORRE, 2008, p.9). Ou seja, o reconhecimento dos tipos documentais ${ }^{7}$ é o primeiro passo para a produção de documentos e, além disso, é também na produção que todas as etapas subsequentes são definidas, isto é, a partir da decisão pelo sistema de organização que será adotado.

[...] os arquivos devem ser reveladores das atividades efetivamente desenvolvidas pelas instituições (ou pessoas) ao longo da sua existência, revalorizando, desse modo, os elementos informais (ao lado dos normativos) como único meio de inserir corretamente os documentos em seu contexto de produção, permitindo assim uma interpretação histórica nos moldes propostos pelo perspectivismo histórico. $\mathrm{O}$ 
estabelecimento de tipologias documentais é fundamental para que esse processo possa ocorrer, representando os primeiros passos em um vasto caminho (LOPEZ, 1999, p. 78).

A partir do estudo da produção documental, é possível identificar tanto os tipos documentais, quanto os fluxos informacionais. Além disso, este estudo permite que a organização dos documentos ocorra com eficiência, garantindo a recuperação de documentos e informações necessários para a gestão administrativa e o processo decisório. Assim, o gerenciamento dos tipos documentais maximiza o uso/aplicação das informações orgânicas na tomada de decisão.

Para Pazin (2005, p. 16), um dos problemas dos arquivistas brasileiros tem sido a inexistência de trabalhos sistematizados de levantamento de tipos documentais comuns às instituições (públicas ou privadas), resultando na falta de instrumental de análise ao profissional que inicia o trabalho de organização de arquivos e que precisa identificar os documentos do seu acervo.

Observa-se que o arquivista precisa conhecer todos os tipos documentais produzidos na empresa, pois este conhecimento subsidia o seu trabalho, tendo em vista que é a partir dele que outras atividades e instrumentos arquivísticos de gestão documental poderão ser desenvolvidos.

Cada organização possui os seus objetivos e metas próprios que variam de acordo com o negócio, a missão e a visão, ou seja, as organizações são diferentes entre si, portanto, os tipos documentais são específicos a cada realidade organizacional. Assim, quando as organizações são similares, ou seja, apresentam características semelhantes, pode-se utilizar o levantamento de tipos documentais dessas organizações como parâmetro, entretanto, adequando o que for necessário (NASCIMENTO, 2014, p. 90).

Segundo Gonçalves (1998, p. 13) “[...] nenhum documento de arquivo pode ser plenamente compreendido isoladamente e fora dos quadros gerais de sua produção ou, expresso de outra forma, sem o estabelecimento de seus vínculos orgânicos". Considerando que documento de arquivo é aquele produzido no desempenho de funções / atividades das instituições, estudá-las é 
elemento básico para compreender os documentos e conhecer as relações existentes entre eles, lembrando que documentos de arquivo não existem isoladamente, ou seja, possuem organicidade.

É importante destacar que para compreender a função dos documentos no momento de sua gênese, há que se compreender o contexto de produção documental, isto é, as funções exercidas pela entidade produtora, e isso pode levar à compreensão de boa parte do significado do conteúdo de cada documento. Em cada documento há o registro de uma mediação específica entre as diversas instâncias, tanto legais quanto administrativas, que interferem na operação de qualquer organismo (PAZIN-VITORIANO, 2012, p. 13).

Assim, compreender o contexto de produção de um documento de arquivo "[...] exige conhecer a história do organismo produtor, abordando-a, principalmente, na perspectiva das funções e atividades por ele desenvolvidas na perspectiva da estrutura e funcionamento do organismo produtor." (GONÇALVES, 1998, p. 20).

Para realizar o estudo do contexto de produção de documentos Gonçalves (1998) defende que,

Antes de tudo, é preciso localizar as fontes de informação privilegiadas para a realização do estudo. [...] A localização e a consulta destas fontes de informação devem, em princípio, resultar na reunião substancial de dados, que sistematizados, permitirão compreender o contexto geral de produção dos documentos. Na sistematização dos dados levantados, será importante, para a organização dos documentos de arquivo, detectar com clareza as funções primordiais assumidas pelo organismo produtor. $\mathrm{O}$ conjunto de funções detectadas envolverá necessariamente, atividades que deve cumprir de forma direta (atividades-fim), bem como atividades que lhe servem como suporte (atividades-meio) (GONÇALVES, 1998, p. 20-21).

Mas além do contexto de produção, é necessário também, identificar, durante o estudo, o vínculo arquivístico de cada documento, conforme preconizado por Luciana Duranti (1997).

No centro da Arquivologia está o conceito de vínculo arquivístico, que é a rede de relacionamentos que cada 
documento (record) tem com outros documentos pertencentes ao mesmo conjunto. $\mathrm{O}$ vínculo arquivístico é originário, porque passa a existir quando um documento é criado (ou seja, quando, após ser elaborado ou recebido, é colocado à parte no fundo da pessoa física ou jurídica que o produziu ou recebeu, para ação ou referência), necessário, porque existe para todos os documentos (ou seja, um documento pode ser considerado um registro somente se adquire um vínculo arquivístico), e determinado, porque é qualificado pela função do documento no conjunto documental ao qual pertence (DURANTI, 1997, p. 215-216, tradução nossa).

O vínculo arquivístico vai além da compreensão do documento dentro de seu contexto de produção porque se refere às ligações funcionais que o documento estabelece na rede de ações administrativas de que faz parte. Tratase de compreender, além do lugar do documento na instituição, conhecer o lugar do documento em relação aos demais documentos para a produção do efeito administrativo, técnico ou legal, a que ele se destina.

Nos arquivos administrativos, esse levantamento deve ocorrer em duas frentes: a primeira pela realização de entrevistas com pessoas ligadas ao organismo produtor e a segunda, com o mapeamento dos depósitos de documentos (PAZIN, 2005, p. 10).

Percebe-se que a identificação da produção documental das empresas envolve duas dimensões: a dimensão técnica, correspondente aos tipos documentais em si, e a dimensão humana, processual, de seus produtores. Partindo desse pressuposto, o bom relacionamento entre o arquivista e os indivíduos dos setores produtores é essencial, uma vez que em caso de necessidade de aplicação de entrevista e questionário, este sujeito não venha a negar informações. Ressalta-se que estas questões também envolvem a cultura organizacional, que pode ser propícia ou não ao compartilhamento de informações. Justamente por isso, perceber todo o ambiente e as pessoas que nele atuam é imprescindível para garantir um bom conhecimento do contexto da produção documental da empresa. 


\section{Produção documental e sua contribuição para a constituição da memória organizacional}

Para utilizar os dados, a informação e o conhecimento como estratégia competitiva nas empresas, os arquivos devem estar organizados de forma que realmente reflitam as funções/atividades desempenhadas por elas. Assim, as informações orgânicas ganham condições de tornar-se subsídio para o processo decisório, auxiliando na obtenção de vantagem competitiva.

A estruturação da memória organizacional garante também que a história da empresa e dos sujeitos que nela atuam esteja registrada. Luciana Duranti, desde 1994, apresentou algumas considerações sobre a dificuldade existente no processo de gestão documental, especialmente no que se refere ao estudo da produção documental das organizações, que ocorrem até os dias atuais. Segundo a autora,

[...] os arquivistas tem grande dificuldade em obter mesmo aqueles documentos sobre os quais têm responsabilidade legal; que eles parecem incapazes de limitar e controlar as distorções das provas documentais causadas pelo processo subjetivo de atribuir valores aos documentos no curso do processo de recolhimento; que eles têm problemas em identificar quais documentos foram realmente criados e usados, e em introduzir controles de guarda para assegurar que aqueles que produzem documentos saibam o que irá constituir provas de suas ações e quais são seus deveres a esse respeito; e, por fim, que a maioria dos arquivistas está completamente mistificada e hipnotizada pelos produtos das novas tecnologias da informação, a ponto de ter grandes problemas não só para distinguir documentos de trabalho, interlocutórios, de documentos oficiais, mas também documentos de simples dados. Acredito firmemente que o fracasso dos arquivistas contemporâneos em enfrentar os registros documentais contemporâneos é devido a uma considerável deficiência no seu conhecimento profissional, deficiência esta existente há longo tempo mas que se tornou evidente com as mudanças no mundo arquivístico decorrentes do uso da tecnologia eletrônica na criação, manutenção e preservação dos registros documentais. (DURANTI, 1994, p. $58)$.

Acredita-se que, passadas mais de duas décadas, essa problemática ainda persiste. A existência dos ambientes digitais não elimina a necessidade do estudo da produção documental, pelo contrário, ele é tão necessário quanto 
antes, principalmente por dois motivos. Primeiro, porque os documentos passam a ser armazenados em suportes em que, aparentemente, não se observa a quantidade de espaço que os documentos estão ocupando, diferente do que acontece quando os documentos estão armazenados em outros suportes tradicionais, como o papel. Em segundo lugar, entende-se que a compreensão sobre o documento enquanto registro das ações administrativas e sobre a diferença existente entre os diversos tipos documentais, de acordo com sua posição na rede de relações estabelecida pelas ações administrativas que ele formaliza, traduz-se na adequada compreensão do valor de cada documento dentro do acervo, no processo de avaliação documental.

O arquivista que realiza um bom estudo da produção documental identifica e conhece os tipos documentais decorrentes das funções e atividades, consegue colocar em prática a GD, GI e GC, podendo recuperar, inclusive, a memória organizacional, já que ela está estritamente ligada ao conhecimento. Isso acontece em razão de que a organização e o armazenamento em si, de documentos e informações, se constituem em repositórios e a memória organizacional vai agir dando um sentido a eles, transformando-os em repertório de conhecimento.

É neste ponto que a gestão documental encontra a memória organizacional. $\mathrm{O}$ estudo da produção documental, como base para as etapas posteriores de classificação e avaliação, contempla o estudo sobre as potencialidades informacionais do documento.

A memória organizacional pode ser entendida como a habilidade das organizações para salvar, reter e fazer uso de informações do passado nas atividades atuais. É um elemento chave que permite que as organizações aprendam dos erros e acertos do passado. Mas fazer uso de este tipo de informação é uma atividade complexa, pois se encontra dispersa dentro da organização em diversos lugares (i.e., nos indivíduos, em documentos, em relatórios, sistemas de informação, etc.) e é heterogênea (i.e., conhecimentos tácito, explícito, mentalizado, codificado, incorporado, embutido, declarativo, procedural, condicional, etc.) (MELGAR-SASIETA; BEPLER; PACHECO, 2011, p. 1). 
Considerando-se a definição utilizada por Melgar-Sasieta, Bepler e Pacheco (2011), acima, entende-se que a memória organizacional nada mais é do que a colocação em uso do acervo documental preservado nos arquivos. Trata-se de ampliar a potencialidade da gestão documental em direção à gestão da informação e do conhecimento, utilizando para isso as ferramentas disponíveis para retenção e disseminação da informação, associadas a um programa de mudança da cultura organizacional.

A figura abaixo apresenta graficamente como se estabelece essa relação:

Figura 1 - Compreensão da produção documental e suas relações.

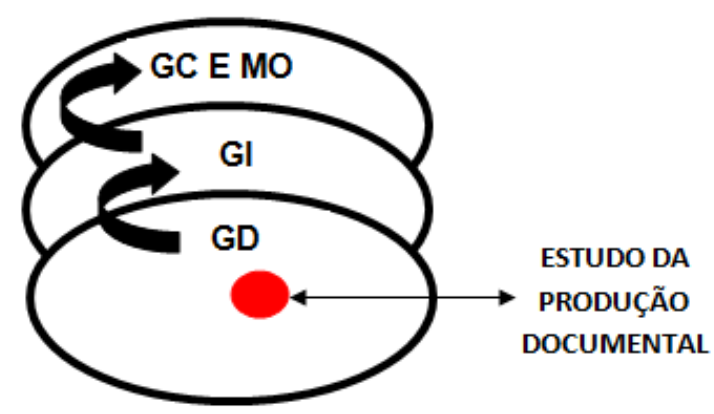

Fonte: Elaborado pelas autoras.

A imagem busca representar como ocorre um processo de complementação entre todos estes sistemas. Não é possível elaborar um programa de GD sem realizar o estudo da produção de documentos; também não é possível trabalhar um sistema de GI se não há um sistema de GD funcionando com eficiência; assim como não é adequado trabalhar a GC sem possuir um sistema de GI que funcione. E, por fim, a função da memória organizacional é subsidiar os processos de GC. Evidencia-se, assim, que o estudo da produção de documentos é essencial para trabalhar com informações e conhecimentos nos ambientes empresariais de maneira consistente.

No que se refere à aproximação da memória organizacional com a gestão do conhecimento, entende-se que, ao desenvolver e implantar mecanismos de registro, a MO tenta coligir o conhecimento individual, com base numa estratégia de linguagem que possibilita o registro de uma estrutura básica de informações para mantê-lo ao longo do tempo. 
Considerando-se que a GC envolve o aspecto gerencial (criação e gerenciamento de modelos, processos, fluxos e ferramentas) e o aspecto de conteúdos (processamento e tratamento e aplicação de técnicas de conversão), a memória organizacional atua principalmente no segundo aspecto, formatando e organizando os conteúdos para disponibilizá-los, o que inclui a criação de mecanismos de busca por informação de forma ativa e passiva pelos usuários.

Nesse sentido, o estudo da produção de documentos se constitui em elemento fundamental porque é onde se inicia todo o tratamento arquivístico, que dará embasamento para a implantação dos processos informacionais posteriores. Lembrando-se que a identificação dos tipos documentais possui uma relação estreita com os fluxos informacionais, tendo em vista que são os tipos documentais que sustentam os fluxos de informações formais e precisam ser mapeados para que haja a identificação das falhas, lacunas ou acertos que ocorrem durante esse fluxo no interior das empresas. Isso contribui para que os fluxos informacionais informais também ocorram com qualidade, já que estes são consequência de um bom fluxo informacional formal.

Uma empresa que possui um programa de GD eficiente certamente consegue embasar os gestores nas decisões organizacionais, diminuindo os riscos de erros. A memória organizacional também contribui com isso, uma vez que possibilita que os gestores acessem as informações retrospectivas, evitando retrabalho e possibilitando o contato com as experiências pregressas da empresa.

\section{Considerações finais}

Os ambientes empresariais são ambientes complexos que mudam constantemente. Dessa forma, quanto mais se conhece sobre a empresa (funções/atividades), seus sujeitos e seus processos, maior a chance dela possuir vantagem competitiva, além do que, valorar os dados, as informações e o conhecimento existente na empresa é questão substancial.

Considerando-se os problemas levantados para a elaboração desse artigo: O que a memória organizacional representa para os ambientes organizacionais? Qual a importância da produção documental para a preservação da memória 
organizacional? - Compreende-se que para usufruir da memória organizacional é preciso primeiramente trabalhar com a gestão documental e a gestão da informação, de modo a transformá-la numa ferramenta para a gestão do conhecimento. Entende-se que é na gestão documental que acontece uma das atividades mais importantes do arquivista nos seus diversos ambientes de atuação, que é o estudo da produção dos documentos.

O estudo do contexto de produção documental vai possibilitar que os profissionais conheçam as funções/atividades desempenhadas pelas organizações por meio da identificação dos tipos documentais, permitindo, consequentemente, que as outras etapas da gestão documental ocorram eficientemente. Ao mesmo tempo, o estudo da tipologia documental é essencial, uma vez que os tipos documentais constituem-se em registros dos fluxos informacionais formais. Sem conhecê-los não se sabe como está se desenvolvendo o fluxo informacional das organizações (se há falhas, lacunas ou acertos). Evidencia-se que este estudo também deve ser realizado com os documentos produzidos em ambientes digitais, tendo em vista que há um gerenciamento específico para esses documentos e em algumas empresas, atualmente, só se trabalha com esse tipo de suporte.

Destaca-se que, para o sucesso do estudo da produção documental, o arquivista precisa construir um bom relacionamento com os sujeitos organizacionais para que o momento de coleta de informações ocorra de maneira efetiva e que colabore para o conhecimento da empresa. Quando a cultura organizacional se constitui em uma cultura aberta ao compartilhamento isso se torna mais fácil para o profissional.

Além disso, o arquivista também precisa apresentar as competências informacionais necessárias para trabalhar com a gestão documental, com a gestão da informação, com a gestão do conhecimento e com a memória organizacional, de modo a que os repositórios se tornem repertórios de conhecimento que auxiliarão as organizações a obterem vantagem competitiva.

O contexto da produção de documentos possui uma relação estreita com todas as atividades que o arquivista desempenha, tendo em vista que é com esse estudo que ele inicia todos os demais processos da Gestão Documental, ou seja, 
se não for realizado, não há a possibilidade de acesso às informações orgânicas, nem será possível disponibilizar as informações retrospectivas com o uso da memória organizacional. Não se consegue constituir uma memória organizacional sem realizar o estudo do contexto de produção documental, uma vez que essa é a base da construção de conhecimento sobre o conteúdo informacional produzido e registrado pela empresa.

E, por fim, acredita-se que a memória se constitui em elemento importante a ser implantado nas empresas por dois motivos principais. Primeiro, porque é por meio dela que a história da empresa e dos indivíduos é preservada, constituindo-se como fonte também para a memória institucional. Segundo, porque ela auxilia as empresas no desenvolvimento de estratégias para a solução de problemas, ou atuando na construção de sentido de dados e informações, de modo a transformar algo estático em subsídios à estratégia competitiva, quando se configura em memória organizacional.

\section{Referências}

BELLOTTO, H. L. Reflexões sobre o conceito de memória no campo da documentação administrativa. In: Arquivos Permanentes: tratamento documental. Rio de Janeiro: FGV, 2004. p. 271-278.

BERNARDES, I. P.; DELATORRE, H. Gestão documental aplicada. São Paulo: Arquivo Público do Estado de São Paulo, 2008. 54 p. Disponível em: $<$ http://amormino.com.br/livros/00000000-gestao-documental-aplicada.pdf $>$. Acesso em: 16 jan. 2015.

BRASIL. Lei no 8.159, 8 de janeiro de 1991. Dispõe sobre a política nacional de arquivos públicos e privados e dá outras providências. Diário Oficial da União, Brasília, 9 jan. 1991. Disponível em:

$<$ http://www.planalto.gov.br/Ccivil 03/LEIS/L8159.htm> Acesso em: 15 abr. 2016.

CARVALHO, E. L. De; LONGO, R. M. J. Informação orgânica: recurso estratégico para a tomada de decisão. Informação \& Informação, Londrina, v. 7, n. 2, p. 113-133, jul./dez. 2002.

COSTA, I. T. M. Memória institucional: a construção conceitual numa abordagem teórico-metodológica. 1997. 169 f. Tese (Doutorado em Ciência da Informação). CNPq/Ibict/UFRJ/ECO, Brasília, 1997. 
DAVENPORT, T.; PRUSAK, L. Conhecimento empresarial: como as organizações gerenciam o seu capital intelectual. 15. Ed. Rio de Janeiro: Elsevier, 2003.

DELMAS, B. Arquivos para quê?. São Paulo: Instituto Fernando Henrique Cardoso, 2010.

DURANTI, L. Registros documentais contemporâneos como provas de ação. Estudos Históricos, Rio de Janeiro, v. 7, n. 13, p. 49-64, 1994.

DURANTI, L. The archival bond. Archives and Museum Informatics.

Vancouver (Canadá): Kluwer Academic Publishers, v.11, p. 213-218, 1997.

ETZIONI, A. Organizações Modernas. São Paulo: Pioneira, 1976.

FREIRE, P. S. et al. Memória organizacional e seu papel na gestão do conhecimento. Revista de Ciências da Administração, Florianópolis, v. 14, n. 33, p. 41-51, ago. 2012. Disponível em:

$<$ https://periodicos.ufsc.br/index.php/adm/article/view/25324>. Acesso em: 21 out. 2016.

GONÇALVES, J. Como classificar e ordenar documentos de arquivo. São Paulo: Arquivo do Estado, 1998. (Projeto como fazer; v. 2).

HOUAISS, A. Grande dicionário Houaiss de Língua Portuguesa. Beta. Rio de Janeiro: Instituto António Houaiss, 2012.

IZQUIERDO, I. Memória. Porto Alegre: Artmed, 2002.

LOPEZ, A. P. A. Tipologia documental de partidos e associações políticas brasileiras. São Paulo: Loyola, 1999.

MACEDO, N. A. M. Criando uma arquitetura de memória corporativa baseada em um modelo de negócio. 2003. Tese (Doutorado em Informática) Programa de Pós-Graduação em Informática, Pontifícia Universidade Católica do Rio de Janeiro (PUC-RJ), Rio de Janeiro, 2003.

MENEZES, EDNA, M. Estruturação da memória organizacional de uma instituição em iminência de evasão de especialistas: Um estudo de caso da CONAB. 2006. 118 f. Dissertação (Mestrado em Gestão do Conhecimento e da Tecnologia) - Universidade Católica de Brasília, 2006.

MIRANDA, R. C. da R. O uso da informação na formulação de ações estratégicas pelas empresas. Ciência da Informação, Brasília, v. 28, n. 3, p. 284-290, set./dez. 1999.

NASCIMENTO, N. M. do. Tipos documentais e fluxos de informação como subsídios para o processo decisório em ambientes organizacionais. 2014. 191f. Dissertação (Mestrado em Ciência da Informação) - Programa de Pós- 
Graduação em Ciência da Informação, Faculdade de Filosofia e Ciências (FFC), Universidade Estadual Paulista (Unesp), Marília, 2014.

NORA, P. Entre memória e história: a problemática dos lugares. Revista Projeto História, São Paulo, n. 10, dez. 1993.

OLIVEIRA, S. Memória Institucional: lugar de (re) construção de uma memória coletiva?. In: SOUTO, L. (Org.). Gestão da Informação e do Conhecimento: práticas e reflexões. Rio de Janeiro: Interciência, 2014.

PAZIN-VITORIANO, M. C. C. Centros de memória empresarial: documentos de arquivo como artefatos da cultura organizacional In: OLIVEIRA, L. M. V.; OLIVEIRA, I. C. B. Preservação, acesso, difusão: desafios para as instituições arquivísticas no século XXI. Rio de Janeiro: AAB, 2013. p. 916-927.

PAZIN-VITORIANO, M. C. C.. Obrigação, controle e memória: aspectos legais, técnicos e culturais da produção documental de organizações privadas. 2012. 355 f. Tese (Doutorado em História Social) - Faculdade de Filosofia, Letras e Ciências Humanas. Universidade de São Paulo, 2012.

PAZIN, M. Arquivos de empresas: Tipologia Documental. Associação de Arquivistas de São Paulo: São Paulo, 2005.

PÉREZ-MONTORO GUTIÉRREZ, M. Identificación y representación del conocimiento organizacional: la propuesta epistemológica clásica. Barcelona: FUOC, 2004.

PONJUÁN DANTE, G. Gestión de información: dimensiones e implementación para el éxito organizacional. Rosario: Nuevo Paradigma, 2004. 208 p.

MELGAR-SASIETA, H. A. M.; BEPPLER, F. D.; PACHECO, R. C. S. A memória organizacional no contexto da engenharia do conhecimento.

DataGramaZero, Rio de Janeiro, v. 12, n. 3, ago. 2011.

SIMIÃO, H. E. Memória organizacional. Curitiba: Companhia de Informática do Paraná, c2009. Disponível em:

<www.batebyte.pr.gov.br/modules/conteudo/conteudo.php?conteudo=1716>. Acesso em: 18 jan. 2016.

VALENTIM, M. L. P. O processo de inteligência competitiva em organizações. DataGramaZero, Rio de Janeiro, v. 4, n. 3, p. 1-24, jun. 2003. VITORINO, E. V; PIANTOLA, D. Competência informacional - bases históricas e conceituais: construindo significados. Ciência da Informação, Brasília, v. 38. n. 3, p. 130-141, set./dez. 2009. 
WILSON, T. D. Information management. In: FEATHER, J.; STURGES, P. International encyclopedia of Information and Library Science. Londres: Routledge, 2003.

\title{
The documents production study and organizational memory in business environments
}

\begin{abstract}
The study of document production allows the archivist to understand which functions and activities are materialized in documents. It is through this study that the document management begins, also enabling the implementation of information management, knowledge management and organizational memory. The objective of this work is to identify how organizational memory contributes to companies and how the document production contributes to the preservation of organizational memory. This work is a qualitative research, exploratory, using as a methodological procedure the bibliographic research. It is evident that organizational memory is closely linked to the information management and knowledge management; it is through its memory that the repositories are transformed into repertoires of knowledge, that support the decision-making process ensuring that organizations gain competitive advantage. As a result, it is understood that the study of documentary production and its context is what will give support to professionals develop organizational memory in enterprise environments.
\end{abstract}

Keywords: Organizational Memory. Document Production. Business Environments. Information Management. Knowledge Management.

Recebido: 04/07/2016

Aceito: 21/09/2016

1 LEHNER, F.; MAIER, R. K. How Can organizational memory theories contribute to organizational memory systems? Information Systems Frontiers, [S.1.], v. 2, n. 3-4, p. 277298,2000

2 JACKSON, P. An exploratory survey of the structure and components of organizational memory. Becoming virtual: Knowledge Management and Transformation of the Distributed Organization, 2007. 
${ }^{3}$ ACKERMAN, M. S.; HADVERSON, C. A. Reexamining organizational memory. Commun. ACM, [S.1.], v. 43, n. 1, p. 58-64, 2000.

4 STEIN, E. W. Organization memory: review of concepts and recommendations for management. International Journal of Information Management, [S.1.], v. 15, n. 1, p. 1732, 1995.

${ }^{5}$ Ropé e Tanguy (1997, p. 16 apud VITORINO; PIANTOLA, 2009, p.132), apoiados numa definição do dicionário Larousse Comercial de 1930, para esclarecer a noção de competência apresentam que "uma das características essenciais da noção de competência é ser inseparável da ação; a competência é o conjunto de conhecimentos, qualidades, capacidades e aptidões que habilitam para a discussão, a consulta, a decisão de tudo o que concerne o trabalho, a qual supõe conhecimentos fundamentados, acompanhados das qualidades e da capacidade que permitem executar as decisões".

ROPÉ, F.; TANGUY, L. (Orgs.). Saberes e competências. Campinas: Papirus, 1997.

"Para ser competente em informação, uma pessoa deve ser capaz de reconhecer quando a informação é necessária e ter a habilidade para localizar, avaliar e usar efetivamente a informação. Pessoas competentes informacionais são aquelas que aprenderam a aprender" (AMERICAM LIBRARY ASSOCIATION, 1989 apud VITORINO; PIANTOLA, 2009, p. 132).

AMERICAN LIBRARY ASSOCIATION. Presidential Committee on Information Literacy: final report. Washington, 1989.

6 "O arquivista, como profissional da informação no processo de Inteligência Competitiva necessita conhecer o setor produtivo, observar as tendências econômicas e mercadológicas de seu país e de outras regiões do mundo vinculadas ao segmento econômico, bem como avaliar constantemente sua competência, potencialidade e conhecimentos sobre a cadeia de produção em que atua [...] precisa interagir com o cotidiano do negócio da empresa [...] oferece suporte à tomada de decisão na busca de vantagem competitiva e na busca de informações críticas e qualificadas, que são analisadas de modo a agregar valor, auxiliando na formulação de estratégias, proporcionando a conexão entre a gestão da informação, a gestão do conhecimento e a inteligência competitiva." (VALENTIM, 2003, p. 17- 18).

7 "A identificação dos tipos documentais desde a produção de documentos é essencial, uma vez que é por meio dela que podemos conhecer mais sobre a organização, sua função, processos, atividades e tarefas que são materializados nos documentos produzidos internamente. Nessa perspectiva, é importante identificar os produtores, as características dos documentos, a datação (época), entre outras características documentais. Pelo reconhecimento dos tipos documentais torna-se possível a obtenção de diferentes informações que, por sua vez, serão determinantes para a organização, porquanto os documentos são uma espécie de espelho da organização e isso significa que, se a documentação está sendo gerenciada eficientemente, ou seja, tratada, organizada, gerenciada, disseminada e acessada com eficiência, a organização estará caminhando bem; entretanto, se a organização não valoriza os documentos produzidos e não reconhece a importância destes para que possa atingir seus objetivos e metas, bem como para auxiliar os gestores na tomada de decisão, de forma que estes possam avaliar entre as alternativas menos consistentes e mais precisas, assim, a organização exposta às mudanças do mercado, terá melhores condições para enfrentar crises e riscos não previstos que serão determinantes para sua existência." (NASCIMENTO, 2014, p. 87-88). 